\title{
A migração venezuelana e o aumento da pobreza em Roraima
}

Fernanda Cláudia Araújo da Silva

Resumo: O fluxo de venezuelanos para Roraima, em especial para as cidades de Pacaraima e Boa Vista, tem ocasionado significativo crescimento das demandas locais. Nesse artigo procura-se analisar as relações entre a situação de vulnerabilidade socioeconômica dos migrantes, o surgimento de um estigma por parte da sociedade roraimense e o aumento da pobreza nas áreas da fronteira brasileira com a Venezuela.

Palavras-Chaves: Migração. Pobreza. Vulnerabilidade. Roraima. Venezuela.

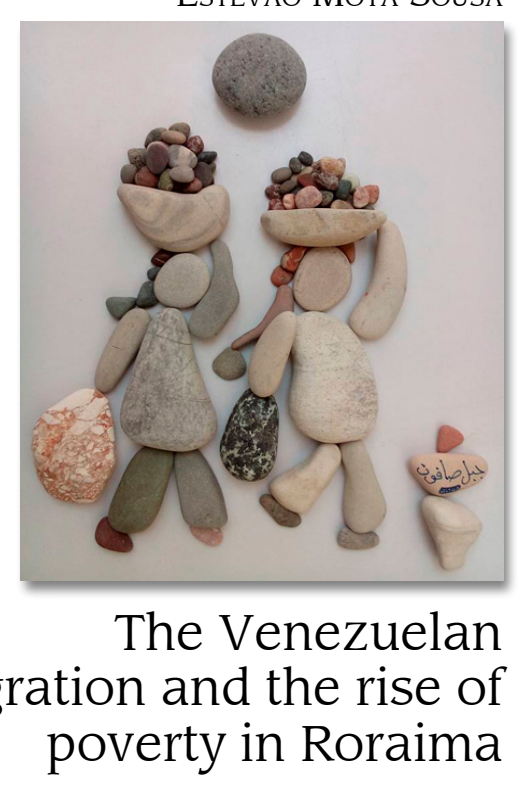

Abstract: The flow of Venezuelans to Roraima, especially to the cities of Pacaraima and Boa Vista, has caused significant growth of local demands. This article seeks to analyze the relationships of the migrants' socioeconomic situation of vulnerability, the emergence of a

$\overline{\text { Fernanda Cláudia Araújo da Silva }}$

Professora do Departamento de Direito Público da Faculdade de Direito da Universidade Federal do Ceará (UFC) E-mail:f.c.araujo@hotmail.com

\section{Estevão Mota Sousa}

Graduando da Faculdade de Direito da Universidade Federal do Ceará (UFC)

E-mail:estevaoms98@gmail.com stigma by the Roraima society and the increase in poverty in the areas of the Brazilian border with Venezuela.

Keywords: Migration. Poverty. Vulnerability. Roraima. Venezuela.
RECEBIDO EM: 30/12/2018

Aprovado EM: 10/03/2019 


\section{INTRODUÇÃo}

A migração venezuelana para o Brasil se estabeleceu em três fases, sendo a primeira composta por integrantes da classe alta; a segunda, por pessoas que faziam parte da classe média, como profissionais liberais e comerciantes; e a terceira, por pessoas desafortunadas, que são identificados sob o prisma da vulnerabilidade.

A cidade brasileira mais próxima do país Bolívar é Pacaraima, por onde entraram (e entram) os venezuelanos, sendo em maior quantidade os da terceira leva, composta por índios e não-índios à procura de ajuda humanitária no Brasil. Dessa forma, a situação deve ser entendida como sendo derivada de um problema político advindo da Venezuela, o qual tem afetado o estado de Roraima, gerando uma mudança de paradigmas sociais e contribuindo com o aumento da pobreza na localidade. Para tanto, é preciso entender que essa movimentação de pessoas tem fins humanitários e que também ensejou a mudança de parâmetros sociais existentes, visto os que chegaram ao Brasil e estão à procura de uma vida melhor.

Essa situação (migração venezuelana) está longe de ter uma solução, parece findar em demandas socioeconômicas no Brasil e alcança diversos problemas como desemprego, prostituição, abandono e outros efeitos deletérios, advindos como resultados existentes das dificuldades da própria pobreza. Porém, o problema migratório tem sido mitigado por organismos internacionais como a Organização Internacional de Migração (OIM) e o Alto Comissariado das Nações Unidas para os Refugiados (ACNUR). No Brasil, existe também a atuação da Polícia Federal e do Exército Brasileiro, o qual, com a Operação Acolhida, tem minimizado a situação dos venezuelanos, com sua distribuição e alocação em diversos outros estados da federação. Há ainda uma legislação pátria que estabelece uma série de direitos e proteções aos migrantes, mas, ao mesmo tempo, apresenta inconsistências reais, quando da ocorrência de um grande fluxo migratório como está a ocorrer em Roraima.

Nesse sentido, será feita uma análise das discrepâncias entre a previsão legal da novel lei migratória (Lei $\mathrm{n}^{\circ}$ 13.445/2017) e a situação gerada em Roraima, com um aumento de demandas sociais e da pobreza na localidade. Dessa forma, procura-se 
analisar a situação da migração venezuelana em Roraima e a identificação do aumento da pobreza local, ante a identificação do trânsito de pessoas em situação de vulnerabilidade, de modo a ensejar respostas à pergunta de partida: a migração venezuelana aumentou a pobreza em Roraima?

Para tanto, o trabalho está dividido em três partes, sendo a primeira acerca da identificação da vulnerabilidade dos venezuelanos ante à situação socioeconômica; na segunda, é feita uma análise sob a ótica da sociedade roraimense; e por último, analisa-se se o aumento da pobreza em Roraima deve-se exclusivamente aos venezuelanos. Quanto ao aspecto metodológico, a pesquisa apresenta um modelo hegeliano, ou seja, dialético, pois parte de conceitos, proposições, sínteses e posturas contraditórias.

\section{A VULNERABILIDADE DE UM POVO DECLARADA PELO GOVERNO BRASILEIRO}

Vulnerabilidade vem do latim vulnerare, que significa ferir, e vulnerabilis, aquilo que causa lesão. Dessa forma, o conceito de vulnerabilidade atribuído aos venezuelanos os considera enquanto seres humanos vulneráveis, que foram feridos, atacados e lesados em seu país de origem e que necessitam de uma proteção maior quando da busca de proteção em outro lugar.

O conceito, quando condicionado ao elemento da dignidade humana, independe da situação cultural, local ou social (BARCHIFONTAINE, 2006) do indivíduo na identificação da situação vulnerável. Numa digressão quanto à utilização da expressão, esta teve maior ênfase a partir dos anos de 1990, ante o crescimento de pessoas com HIV (BARCHIFONTAINE, 2006) entre populações socioeconomicamente desfavoráveis. Outrora, a adjetivação era utilizada para pessoas deficientes físicas e mentais, crianças abandonadas ou que se encontravam em abrigos.

A expressão retorna à aplicação de migrantes que se sujeitam à situação de fragilidade advinda de uma opressão de qualquer tipo, seja com o comprometimento de sua dignidade, seja com o de preceitos democráticos, seja com a violação de direitos fundamentais. Nessa perspectiva, há a identificação da vulnerabilidade dos 
venezuelanos mesmo que identificados como economicamente favoráveis, ${ }^{1}$ pois existe a violação de direitos fundamentais no seu país de origem.

Desde 2014, a Venezuela enfrenta uma crise político-econômica (SOUZA; SILVEIRA, 2018) a ensejar uma migração para diversos países da América Latina, além de Caribe, Espanha e Estados Unidos:

Tal aumento também é visível no Brasil, principalmente quanto ao fluxo migratório de venezuelanos ao Estado de Roraima. A falta de estrutura do país e a desigualdade social existente entre os próprios nacionais tornam o enfrentamento da situação ainda mais difícil e desafiador. (SOUZA; SILVEIRA, 2018, p. 115).

O Brasil não está incluído entre os principais destinos migratório; no entanto, o quantitativo de emigrantes no Brasil aumentou exponencialmente, tanto que, desde 2016, foi registrado pela Polícia Federal aproximadamente 183.397 entradas $^{2}$ e 111.818 saídas $^{3}$ de migrantes venezuelanos entre Pacaraima, cidade de fronteira do estado de Roraima e a Venezuela (no lado da Venezuela a cidade de fronteira é Santa Elena de Uairén $)^{4}$, sem se falar nos pedidos de refúgio venezuelano:

Tabela 1 - Pedidos de Refúgio no Brasil por Venezuelanos

\begin{tabular}{|c|c|c|c|}
\hline ANO & 2015 & 2016 & $2017\left(^{*}\right)$ \\
\hline PEDIDOS DE REFUGIO & 829 & 3.368 & 7.600 \\
\hline
\end{tabular}

${ }^{*}$ ) Valores computados até junho de 2017.

Fonte: Simões et alli (2017).

1 Isso porque parte-se do pressuposto de uma identificação da migração dos venezuelanos para o Brasil em três níveis, o que se denomina de primeira, segunda e terceira "leva". A primeira leva migratória ocorre com venezuelanos com condições econômicas e que migraram logo no início dos problemas sociais existentes no Estado Bolívar, como empresários e pessoas de classe social rica. A segunda leva compreende profissionais liberais e a terceira, pessoas mais fragilizadas economicamente. No entanto, mesmo ante a identificação de venezuelanos abastados economicamente entre os migrantes, a fragilidade está na violação de direitos fundamentais e dos preceitos democráticos. Portanto, a questão socioeconômica é irrelevante para a atribuição do conceito de vulnerável a esses migrantes.

2 Esse valor é aproximado, pois diversos venezuelanos entram no Brasil sem nenhum registro junto à Polícia Federal.

3 As saídas ocorrem, porque os venezuelanos vêm trabalhar no Brasil e levam para seus familiares gêneros alimentícios, vestimentas e medicamentos.

4 Cf. ACNUR (2018). 
Entre os anos de 2015 e 2016, o aumento de migrantes foi $306,2 \%$, enquanto, entre os anos de 2016 e meados de 2017, o aumento foi de $125,6 \%$. Numa comparação entre 2015 e junho de 2017 , o aumento foi de $816,7 \%$. Esse percentual refere-se aos pedidos de refúgio, mas muitos migrantes não o solicitam e outros sequer fazem qualquer registro junto à polícia de fronteira. Em 2018, o ACNUR informou que, somente em fevereiro de 2018, 24.818 venezuelanos solicitaram refúgio ${ }^{5}$ e 10.963 solicitaram residência ${ }^{6}$ temporária (SIMÕES et alli, 2017). Solicitantes venezuelanos se enquadram na categoria de refugiado estabelecida pela Lei no 9.474/97.

A situação é calamitosa e o estado de Roraima não tem suportado esse fluxo de pessoas, por conta de sua situação administrativa, principalmente na área da saúde pública, tanto que declarou estado de emergência na cidade de fronteira (PARACAÍMA, 2018). Quantitativamente, Roraima tem uma população de 496.936 pessoas, sendo 326.414 em Boa vista e 12.375 em Pacaraima.

Em 2018, o Governo Federal assinou termo de ajuda à saúde pública de Roraima, com a proposição de diversas ações para atendimento de imigrantes:

As ações já estão sendo feitas desde que observamos o aumento da demanda no SUS. Esse Plano clareia e direciona as responsabilidades para cada ente federativo. Na parte do Governo Federal, liberamos, no total, $\mathrm{R} \$ 160$ milhões de recursos de emendas parlamentares para apoiar com mais financiamento o atendimento e também aumentamos o teto para média e alta complexidade, ou seja, os recursos existem e precisam ser bem aplicados", destacou o ministro Ricardo Barros. Dentre as medidas, para orientar o migrante onde buscar o atendimento, o Ministério da Saúde produziu materiais bilíngue (português

5 Nem todos os migrantes se enquadram na situação de refugiados, segundo a lei brasileira $n^{\circ}$ 9474/1997.

6 "Art. $1^{\circ}$ Poderá ser concedida residência temporária, pelo prazo de até 2 anos, ao estrangeiro que tenha ingressado no território brasileiro por via terrestre e seja nacional de país fronteiriço, para o qual ainda não esteja em vigor o Acordo de Residência para Nacionais dos Estados Partes do MERCOSUL e países associados" (BRASIL, 2017). 


\begin{abstract}
e espanhol) com informações sobre acesso e cuidados de doenças prioritárias e agravos de saúde, como difteria. A distribuição é de atribuição do estado e municípios e na fronteira de Pacaraima será o Posto da Agência Nacional de Vigilância Sanitária (ANVISA) que apoiará o migrante. (MACIEL; VALADARES, 2018, s/paginação).
\end{abstract}

Contudo, a situação proporcionou a declaração de vulnerabilidade, de forma que o Governo Federal, por meio do decreto $\mathrm{n}^{\circ}$ 9.285/2018, ao mesmo tempo em que declarou a situação de vulnerabilidade, definiu-a como absoluta (numa presunção iure et de iure), independentemente de qualquer condição social ou outra condição migratória dos venezuelanos no Estado brasileiro.

A presunção assume um caráter absoluto, compatível com a nova lei migratória, a qual traz uma proposta humanitária e, principalmente, assume uma postura proativa no que se refere ao acolhimento de migrantes. Nesse sentido, Fernanda Silva e Diego Marques (2018, p. 06) asseveram que o Brasil "sempre assumiu essa postura protetiva de direito dos refugiados, desde um período não democrático, mas com um acolhimento humanitário" e não seria agora ante à legislação.

\title{
3 DISCRIMINAÇÃO E ESTIGMA DO VENEZUELANO EM RORAIMA
}

O recebimento de pessoas ante um fluxo crescente modifica a estrutura do Estado e chama a atenção da sociedade, principalmente por existirem políticas públicas pré-estabelecidas e eficazes de migração. A sociedade não entende esse deslocamento espacial para o Brasil como parte das estratégias de sobrevivência e de mobilidade social dos venezuelanos. Isso quer dizer que a sociedade recebedora passa a ter um sentimento mal definido acerca da situação, principalmente pela convivência dessas pessoas em praças, rodoviárias, abrigos, mercados e feiras, a transmitir um ar de sofrimento e abandono.

A situação gerou em Roraima, principalmente em Boa Vista, uma postura de rejeição à migração venezuelana, o que não seria uma novidade ante às migrações atuais. Ao contrário, essa rejeição 
tem sido um sentimento contínuo e persistente, ao reconhecer a situação de vulnerabilidade dos venezuelanos como sendo associada à pobreza, à miséria, à violência e a todas as formas de exploração comumente relacionadas com a migração - muitas vezes, de modo ainda mais exacerbado.

O deslocamento de venezuelanos para o Brasil e para diversos outros países da América Latina e do Caribe tem sido inevitável, em face da postura do governo Nicolás Maduro. Além disso, esse descolamento vem arrastado por um conceito negativo de oneração por parte do Estado brasileiro, que vem sofrendo com problemas administrativo-financeiros nos últimos anos e não possui perspectiva de aproveitamento laboral do povo bolívar. Contrário a tal sentimento, há aqueles que afirmam que:

O Estado tem, sim, de coexistir com outras estruturas, acima e abaixo do seu âmbito; tem de se inserir no contexto cada vez mais complexo e concorrencial, numa "rede de poderes públicos"; e tem de repensar as suas funções, os seus meios de agir, muitas das suas fórmulas jurídico políticas (MIRANDA, 2011 apud PIFFER, 2014, p. 54)

Tal pensamento não se mostra aplicado, pois os migrantes são tidos como indesejados e são rejeitados pela sociedade. Não só pela etnia (como ocorrem com os índios venezuelanos), mas por outras razões como língua, religião, aparência, hábitos e outras particularidades. ${ }^{7}$ Esses migrantes são vistos também como competidores de empregos ou ainda como sendo aqueles que aumentam as demandas sociais e de políticas públicas, sendo, portanto, considerados uma ameaça à estabilidade político-social e à segurança brasileiras. ${ }^{8}$

7 Em outros países, gera-se um sentimento anti-imigrante, como ocorre nos Estados Unidos da América.

8 Segundo Balman e Donskis (2014, p. 28): “O tratamento dos estrangeiros como simples "problema de segurança" é subjacente a uma das causas do verdadeiro "moto-perpétuo" nos padrões de interação humana. [...] Em geral, o principal efeito da obsessão com a segurança é o rápido crescimento (e não a redução) da sensação de insegurança, com todos os acessórios de pânico, ansiedade, hostilidade, agressão, mais o esvaziamento ou supressão dos impulsos morais". 
Os migrantes concorrem no mercado de trabalho com a população local, ensejam a redução salarial tanto pela necessidade como pela falta de qualificação, afetando a seara econômica. Entretanto, a questão do estigma e o repúdio à situação decorrem do denominado aglomerado venezuelano em locais públicos, como praças e a rodoviária de Boa Vista, além da quantidade de doenças infectocontagiosas trazidas pelos migrantes que procuram os hospitais públicos.

A prostituição é outro problema gerado pela migração (OITENTA..., 2018), pois as venezuelanas que oferecem seus serviços ficam na Rodoviária Internacional ${ }^{9}$ do bairro Caimbé. ${ }^{10}$ As prostitutas venezuelanas são mulheres casadas (que desempenham a atividade com ou sem a autorização do marido), ${ }^{11}$ solteiras, algumas delas com nível superior, que, por não encontrarem trabalho formal, acabam por se prostituir. A prostituição na localidade acompanhou o deslanchamento do tráfico de drogas, o que agrava mais ainda a questão da segurança nas localidades, principalmente pela entrada significativa de migrantes delinquentes. Várias cadeias públicas e presídios em Roraima foram abertos, em virtude da falta de dinheiro para sustentar a estrutura administrativa, facilitando a entrada de criminosos venezuelanos no Brasil. Entretanto, pesquisas já apontam que a participação desses migrantes venezuelanos na criminalidade comprovada é a mesma, em termos proporcionais, que a da população local (MÁRMORA, 2000).

Tem causado repulsa social a maior incidência de doenças, drogas, prostituição, demandas sociais e aspectos culturais, ${ }^{12}$

9 É considerada internacional, porque ônibus e táxis saem de lá em direção à Guiana Inglesa.

10 Na localidade, já existia prostituição, mas com a vinda das venezuelanas, a situação aumentou demais. Essas venezuelanas passaram a ser chamadas de "oitentas", pois cobravam $\mathrm{R} \$ 80,00$ (oitenta reais) por programa. Atualmente, elas cobram R $\$ 100,00$ (cem reais), mas continuam sendo identificadas como as "oitentas", de modo a serem diferenciadas das prostitutas brasileiras.

11 "Tenho dois filhos na faculdade, um estuda Direito e outro Engenharia. Eles não sabem o que eu faço para viver. Eles me ligam e dizem: mãe eu quero um ténis (sapatilhas), mãe preciso de uma roupa. Tento mandar dinheiro, mas aqui [no Brasil] as coisas são caras." (OITENTA..., 2018, s/paginação).

12 Principalmente por causa dos índios waraos que têm o hábito de pedir esmolas em semáforos, ruas, praças e supermercados. 
como também as ações do próprio governo do estado de Roraima, que tentou fechar a fronteira com a Venezuela ${ }^{13}$ e baixou decreto proibindo o acesso dos venezuelanos aos serviços públicos brasileiros, o que se deu com a edição do decreto $n^{\circ}$ 25.681-E do estado de Roraima, e a decisão ${ }^{14}$ do juiz federal da $1^{\text {a }}$ Vara de Boa Vista, a qual perdeu seu efeito com a análise da decisão na ação em curso junto ao Superior Tribunal Federal (STF).

De qualquer forma, a situação tem ocasionado um sentimento anti-imigratório contra os venezuelanos, seja por conta da situação gerada nas principais cidades de Roraima, seja por conta do próprio governo estadual, que, com suas posturas político-administrativas, tem estimulado reações populares xenófobas e de repulsa aos venezuelanos, até mesmo contrárias aos interesses do Brasil, como estabelecido na nova lei migratória, norma protetiva dos refugiados e em outros documentos de que o Brasil é signatário.

\section{O AUMENTO DA POBREZA EM RORAIMA: CULPA DOS VENEZUELANOS?}

Martinez (2018) apresenta que o maior índice de desemprego brasileiro se deu em Roraima nos últimos anos, assim como dispõe graficamente o crescimento/ a retração da taxa de desocupação, estando o estado com um crescimento nunca visto antes.

13 Ação Civil Originária - ACO n 3121-RR, no âmbito do Supremo Tribunal Federal (STF), diz respeito a pedido de tutela antecipada, para determinar à União o fechamento da fronteira do Brasil com a Venezuela e cumulou um pedido de tutela específica para que a União promovesse medidas administrativas no controle migratório e principalmente, na vigilância sanitária.

14 "Na contramão dos deveres assumidos no âmbito do Direito Internacional, foi publicado o Decreto Estadual n. 25.681-E, de 01 de agosto de 2018, assinado pela Governadora do Estado de Roraima, tornando mais rígido o acesso de migrantes e refugiados oriundos de países não integrantes do Mercosul aos serviços públicos, nos quais se incluem aqueles relacionados à saúde, bem como expondo-os a uma situação de possível deportação/expulsão, à revelia do procedimento legal" e, "DO EXPOSTO e com base decido liminarmente: no poder geral de cautela (a) suspender os efeitos dos Artigos $2^{\circ}, 3^{\circ}$, parágrafo único, e $5^{\circ}$ do Decreto Estadual $n^{\circ} 25.681-E$, de $1^{\circ}$ de agosto de 2018 (DOE $n^{\circ} 3287$, de 1/8/2018, pág.2), naquilo que impliquem discriminação negativa em relação aos imigrantes venezuelanos ou sua deportação ou expulsão", mas, também determinou o fechamento da fronteira que teve a decisão revista pelo STF. 
Em contrapartida, a Federação do Comércio de Roraima (FECOMÉRCIO-RR) analisou dados do Instituto Brasileiro de Geografia e Estatística (IBGE) referentes ao estado e publicou um estudo que conclui que Roraima teve o segundo maior crescimento na taxa de desocupação, entre 2017 e 2018:

Gráfico 1 - Dados relacionados ao desemprego (taxa de desocupação)

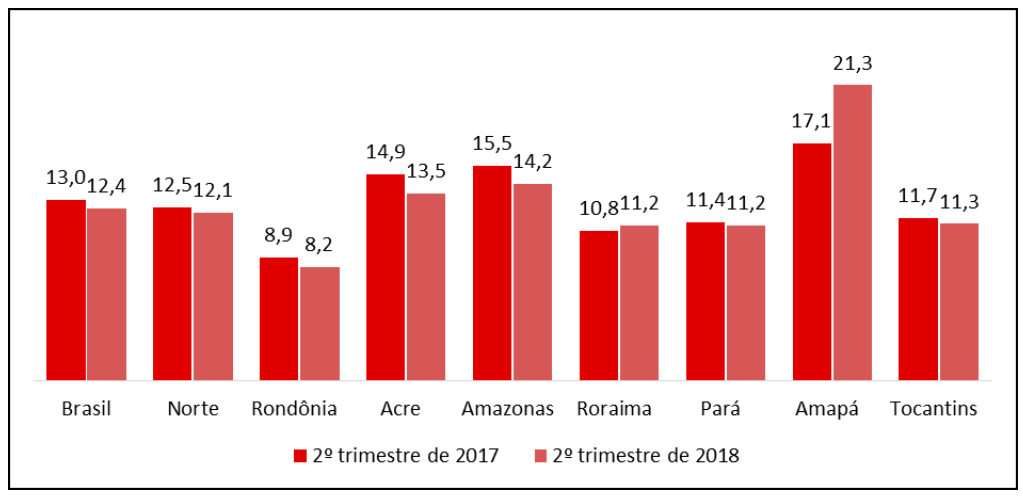

Fonte: (MARTÍNEZ, 2018) ${ }^{15}$

Seja pelo problema da defasagem na economia nacional, seja pelo quantitativo de venezuelanos no estado, há um aumento na taxa de desocupação (desemprego) e, consequentemente, no aumento da pobreza.

Dentro dessa correlação, foi possível estabelecer um liame dentro de uma pesquisa promovida pelo Conselho Nacional de Imigração (CNIg), com o apoio do ACNUR, do Observatório das Migrações Internacionais (OBMigra) e com a execução da Cátedra Sérgio Vieira de Melo da Universidade Federal de Roraima (CSVM/ UFRR) (SIMÕES et alli, 2018). A pesquisa apresentou o seguinte perfil sócio-demográfico:

15 E estabelece que: "Roraima continua sendo o segundo Estado da Região Norte com a menor taxa de desocupação, atrás apenas de Rondônia com 8,2\% e empatado com o Pará. Apesar disso, a taxa de desocupação apresentada no $2^{\circ}$ trimestre de 2018 foi a mais alta já registrada neste período, nunca antes o desemprego tinha superado a marca dos 11\%" (MARTíNEZ, 2018, s/paginação). 
Quadro 1 - Perfil sócio-demográfico dos venezuelanos

- Imigração majoritariamente jovem (72\% do total entre 20 e 39 anos), predominantemente masculina (63\%) e solteira (54\%);

- A crise econômica e política é apontada por $77 \%$ dos participantes como o principal motivo para emigrar. 67\% dos entrevistados imigraram para o Brasil em 2017;

- A imigração é oriunda de 24 regiões venezuelanas, embora com concentração de três estados: Bolívar (26\%), Monagás (16\%) e Caracas (15\%);

- Os migrantes chegaram em sua maioria de ônibus e levaram uma média de 1 a 2 dias para chegar em Pacaraima, no lado brasileiro da fronteira;

- Uma parcela significativa (58\%) conta com redes migratórias composta em sua maioria por amigos e familiares que já residem no Brasil;

- Os imigrantes apresentam bom nível de escolaridade (78\% com nível médio completo e 32\% com superior completo ou pós-graduação);

- Os venezuelanos em Roraima apresentam pouco conhecimento do Português e muitos não estudam o idioma;

Fonte: Simões et alli (2018).

Analisando o perfil descrito na pesquisa, na relação pobreza e na taxa de desocupação (desemprego), há fatores que merecem ser discutidos. O primeiro deles é a faixa etária dos migrantes, que se encontram entre 20 e 39 anos, considerada a idade laboral do mercado de trabalho jovem, o que levaria à sua identificação como desempregados.

É importante lembrar que esses dados são de venezuelanos com registro, ou seja, aqueles que passaram pelo crivo migratório ou, pelo menos, se sujeitaram ao fornecimento de documentos. Sendo assim, os "idocumentados" (KYMLICKA, 2006) ${ }^{16}$ não

16 Will Kymlicka (2006) diz que os "idocumentados" são aqueles que não têm os documentos exigidos pela migração e, por isso, são considerados ilegais. Dessa forma, ele critica a atribuição pejorativa de "ilegais" a esse grupo de pessoas, pois elas não cometeram nenhum crime ou delito, sendo consideradas uma aberração do direito internacional. 
estariam nesse estudo, para fins de correlação à demanda de ociosidade laboral. Não há juridicamente uma idade laboral, existe apenas uma idade mínima para trabalhar e um limite mínimo para a inatividade (aposentadoria), mas se pressupõe que esse seria o momento do auge profissional dessas pessoas, principalmente porque, na sua maioria, são homens solteiros. Além disso, 77\% dos entrevistados estão no Brasil por causa da crise econômica na Venezuela, os outros 23\% foram motivados por questões de saúde (doença em si ou em pessoa da família), causas familiares ou mesmo por razões políticas advindas do regime ditatorial Maduro.

O outro fator importante é a escolaridade dos venezuelanos: 78\% possui nível médio completo, incluindo aqui os de escolaridade técnica, enquanto os demais (32\%) têm nível superior completo ou pós-graduação. ${ }^{17}$ É claro que a desocupação é uma das causas da pobreza na sociedade brasileira, mas não é a única. Outros fatores que contribuem com a pobreza devem ser levados em consideração, como o não crescimento da economia nacional, mesmo com o avanço do Produto Interno Bruto nacional (PIB), entre os anos de 2017 e 2018, pois, em anos anteriores, houve retração no PIB nacional, trajetória negativa da renda e do crescimento econômico.

A falha na absorção de trabalhadores pelo mercado de trabalho $^{18}$ talvez seja o principal motivo para o aumento da pobreza,

17 As porcentagens somadas resultam em 110\%, no entanto os dados não foram modificados.

18 "O estudo do enclave migrante é duplamente importante: ele representa, por um lado, o paradigma da fixação dos imigrantes e, por outro lado, um mercado de trabalho interno para uso exclusivo da força de trabalho migrante, que se mantém isolado da estrutura principal da sociedade. Inicialmente, as oportunidades são mínimas e restringidas pela exiguidade da comunidade migrante. À medida que esta aumenta, são 'invadidos' bairros tradicionalmente nativos; os comerciantes que aí estavam instalados, descontentes com a nova clientela, trespassam os seus negócios para os pequenos 'empresários' migrantes que conseguem, assim, controlar partes significativas do mercado local e regional; surgem, dentro das economias industriais, enclaves migrantes, cujas actividades principais são, preferencialmente, a venda de artigos tradicionais do local de origem (artesanato, restaurantes,...) , as agências de viagens e o fornecimento de serviços legais e médicos. Por outro lado, em mercados muito expostos às flutuações da procura, é frequente os grandes produtores controlarem um vasto leque de empresas subcontratadas, que utilizam como amortecedoras de ciclos económicos. O mercado em que operam tais empresas, não conhecendo barreiras à entrada (do tipo dimensão-mínimaóptima), é o local propício para o estabelecimento das empresas geridas por 
pois, se o PIB tivesse crescido mais expressivamente e sem o aumento do desemprego, a economia nacional teria crescido e a taxa de pobreza, diminuído - mas isso não aconteceu. No caso do Roraima, como houve um aumento de pessoas em busca de emprego, contribuiu-se com o aumento da taxa de pobreza local.

Sabe-se que o desemprego é uma realidade não só da sociedade brasileira, mas de diversos países ocidentais contemporâneos e que pode ter, dentre suas razões agravantes, diversos fenômenos, dentre eles a migração. Esta, por ser evento muito intenso nos últimos anos em Roraima, tornou-se muito visível diante das transformações existentes e com repercussão na seara do trabalho, sobretudo nos últimos anos, com consequências que devem ser levadas em consideração (BECK, 2000), quando da realização de políticas públicas.

\section{CONSIDERAÇÕES FINAIS}

Por mais que se mensurem as políticas de proteção aos migrantes pelo governo brasileiro, a situação do crescimento da pobreza e do desemprego, em Roraima, está ligada ao fluxo migratório. Há uma quantidade de pessoas na localidade em situação de vulnerabilidade, de forma a contribuir para a situação de pobreza e marginalização na capital e em outras cidades, com o aumento de situações de risco. Sendo assim, não se discute mais acerca da vulnerabilidade desses migrantes venezuelanos, principalmente quando incluídos nesse contexto de desemprego.

A situação está longe de ser corrigida, mesmo com tudo que o Brasil tem feito nas suas políticas migratórias. Deu-se destaque à Operação Acolhida do Exército brasileiro; ao programa de interiorização dos venezuelanos, redistribuindo-os para outras cidades brasileiras; assim como à ajuda de organismos internacionais, principalmente o ACNUR, a OIM e diversas organizações não-governamentais de ajuda humanitária. No entanto, a demanda ainda continua.

migrantes, que beneficiam dos laços étnicos (lealdade, obrigação, honra, ...) para reunir trabalho e capital a baixos custos e produzir a preços competitivos." (MATOS, 1993, p. 14). 
A postura adotada pelo Brasil e pelas organizações internacionais tem sido relevante para o controle da situação, mas a Venezuela precisa intervir mais para que a situação enseje, pelo menos, modificações na economia daquele país e afete menos diversos outros Estados, como Brasil e Colômbia.

\section{REFERÊNCIAS}

ACNUR - Alto Comissariado das Nações Unidas para Refugiados. Venezuela Situation: supplementary appeal responding to the needs of people displaced from Venezuela. Genebra: [s.n.], 2018. Disponível em: <https://data2.unhcr.org/en/documents/download/63088>. Acesso em: 14 out. 2018.

BARCHIFONTAINE, C. de P. di. Vulnerabilidade e dignidade humana. $\mathbf{O}$ Mundo da Saúde, São Paulo, a. 30, n. 3, p. 434 -440, 2006. Disponível em: <https://www.saocamilo-sp.br/pdf/mundo_saude/38/vulnerabilidade_ dignidade.pdf>. Acesso em: 13 out. 2018.

BAUMAN, Z.; DONSKIS, L. Cegueira Moral: a perda da sensibilidade na modernidade líquida. Rio de Janeiro: Zahar, 2014.

BECK, U. The Brave New World of Work. Cambridge: Polity Press, 2000.

BRASIL. Lei no 13.445, de 24 de maio de 2017. Institui a Lei de Migração. Disponível em: <http://www.planalto.gov.br/ccivil_03/_ato20152018/2017/lei/L13445.htm>. Acesso em: 13 ago. 2018.

KYMLICKA, W. Fronteras territoriales. Madrid: Editorial Trotta, 2006.

MACIEL, V.; VALADARES, C. Roraima tem plano de ações para atendimento aos imigrantes. Ministério da Saúde, [online], 15 jan. 2018. Disponível em: $\quad<$ http://portalms.saude.gov.br/noticias/agencia-saude/42320roraima-tem-plano-de-acoes-para-atendimento-aos-imigrantes $>$. Acesso em: 14 out. 2018.

MÁRMORA, L. Perspectivas migratorias en el proceso de globalización. In: SCALABRINIANAS, I. M. (org.). Migrações contemporâneas: desafios à vida, à cultura e à fé. Brasília: Centro Scalabriano de Estudos Migratórios, 2000. p. $86-102$.

MARTINÉZ, F. R. Desemprego em Roraima atinge o maior nível desde 2012. Fecomércio RR, [online], 20 ago. 2018. Disponível em: <https:// fecomerciorr.com.br/artigo-tecnico-26-2018-desemprego-em-roraimaatinge-o-maior-nivel-desde-2012/>. Acesso em: 14 out. 2018. 
MATOS, C. Migrações: decisões individuais e estruturas sociais. SOCIUS Working Papers, Lisboa, n. 5, p. 01 - 23, 1993. Disponível em: <https:// www.repository.utl.pt/bitstream/10400.5/1599/1/cm-wp935.pdf>. Acesso em: 15 out. 2018.

MIRANDA, J. de. Teoria do Estado e da Constituição. 3 ed. Rio de Janeiro: Forense, 2011.

OITENTA reais: o "preço" das venezuelanas que sobrevivem da prostituição no norte do Brasil. RTP Notícias, [online], 07 set. 2018. Mundo. Disponível em: <https://www.rtp.pt/noticias/mundo/oitenta-reais-o-preco-dasvenezuelanas-que-sobrevivem-da-prostituicao-no-norte-do-brasil_ n1097557>. Acesso em: 14 out. 2018

PARACAIMA. Decreto executivo n 36, de 29 de setembro de 2017. Declara situação de emergência social no Município de Pacaraima, devido o intenso processo de imigração dos indígenas da etnia Warao, oriundos da Venezuela, acampados em área pública, submetidos à situação de risco pessoal e social, em especial, crianças adolescentes e idosos. Disponível em: http://multiprefeitura.com.br/storage/municipio/5/publicacoes/ dCDhBGBVyGPYcyHC9j5ScmwOBqUdyVtfeNw3roXb.pdf. Acesso em: 14 out. 2018.

PIFFER, C. Transnacionalidade e imigração: a possibilidade de efetivação dos direitos humanos dos transmigrantes diante de decisões de regresso na Itália e na União Europeia. 2014. 345f. Tese (Doutorado em Ciência Jurídica) - Programa de Pós-Graduação Stricto Sensu em Ciência Jurídica, Centro de Educação em Ciências Sociais e Jurídicas, Universidade do Vale do Itajaí, Itajaí, 2014. Disponível em: <http://siaibib01.univali.br/ pdf/Carla\%20Piffer.pdf>. Acesso em: 13 out. 2018.

SILVA, F. C. A. da S; MARQUES, D. J. F. A fronteira brasileira na proteção dos refugiados. In: Colóquio Internacional de Dinâmica de Fronteiras, 2., 2018, Toledo. Anais... Toledo: [s.n.], 2018. p. 225 - 234.

SIMÕES, G. et alli. Resumo executivo. Perfil socidemográfico e laboral da imigração venezuelana no Brasil. Brasília, DF: Conselho Nacional de Imigração, 2017. Disponível em: <http://www.abep.org.br/site/index. php/noticias/347-perfil-sociodemografico-e-laboral-dos-imigrantesvenezuelano>. Acesso em: 14 out. 2018.

SOUZA, A.; SILVEIRA, M. de C. P. da. O fluxo migratório de venezuelanos para o Brasil (2014 - 2018). Cadernos PROLAM/USP, São Paulo, v. 17, n. 32, p. 114 - 132, 2018. Disponível em: <>. Acesso em: 14 out. 2018. 